\title{
Passivation capability of carbon black layers for screen-printed battery applications with Ag current collectors
}

\author{
Patrick Rassek $^{1,3,5}$, Erich Steiner ${ }^{2}$, Timothy C. Claypole ${ }^{3}$, Martin Krebs ${ }^{4}$ and \\ Michael Herrenbauer ${ }^{1,2}$ \\ ${ }^{1}$ Department of Packaging Technology, Stuttgart Media University, D-70569, Stuttgart, Germany \\ ${ }^{2}$ Innovative Applications of the Printing Technologies, Stuttgart Media University, D-70569, Stuttgart, Germany \\ ${ }^{3}$ Welsh Centre for Printing and Coating, College of Engineering, Swansea University, Swansea, SA2 8PP, United Kingdom \\ ${ }^{4}$ VARTA Microbattery GmbH, Innovative Projects, D-73479, Ellwangen, Germany \\ ${ }^{5}$ Author to whom any correspondence should be addressed \\ E-mail: rassek@hdm-stuttgart.de
}

ORCID iDs:

Timothy C. Claypole 0000-0003-1393-9634

Michael Herrenbauer 0000-0003-1391-5026

Patrick Rassek 0000-0003-0694-7644

Keywords: printed flexible batteries, current collectors, corrosion, electrochemistry, cyclic voltammetry, electrochemical passivation

Supplementary material for this article is available

\begin{abstract}
Screen-printed thin-film batteries comprise of current collectors typically realised with commercially available conductive silver inks primarily designed for non-critical printed electronics applications. The avoidance of electrochemical interaction of metallic silver with the respective battery chemistry requires printing of an additional passivation layer. The wide range of printing inks available makes it difficult for researchers to select and qualify battery specific inks that ensure a long-life cycle without limitation of relevant battery performance parameters. This study presents a novel method to quantify the passivation capability of carbon black passivation layers for silver current collectors in $6.0 \mathrm{M}$ potassium hydroxide and $5.8 \mathrm{M}$ zinc chloride aqueous electrolyte solutions. Cyclic voltammetry is used to determine possible electrochemical interaction of passivated current collectors with the electrolyte media which constitute battery performance degrading parasitic side reactions. An innovative approach based on Faraday's law of electrolysis is presented to transform cyclic voltammogram curve progressions into comparable numerical values. The mathematical approach allows quantitative comparison of individually fabricated passivation layers with respect to their passivation capability instead of interpreting a large number of cyclic voltammograms.
\end{abstract}

\section{Introduction}

Wearable self-powered health-monitoring patches [1-5] and flexible smart packaging devices for cold chain logistics [6-9] are innovative printed electronics applications expected to be implemented in large volume markets. Printed batteries with customised voltage levels and discharge capacities are predestined to act as life cycle specific power sources for proper device operation [10-19].

In recent years, advances in material sciences and fabrication techniques resulted in considerable improvements of printed battery performance metrics. The primary zinc-manganese dioxide $\left(\mathrm{Zn} \mid \mathrm{MnO}_{2}\right)$ battery is still one of the most promising battery chemistries for printed electronics applications [10, 14, 20-29]. Due to the increased battery potential, focus is shifted towards printable primary and secondary lithium-ion batteries (LIB) [26, 30-33]. In comparison to performance metrics of conventional secondary batteries, reduced cycle durability of printed battery systems is attributable to present material and process specific limitations. While Wendler et al. [24] report on alkaline nickel-metal hydride $(\mathrm{Ni} \mid \mathrm{MH})$ batteries conducting six discharge/charge cycles, five respectively 12 cycles were demonstrated for printed silver-zinc (Ag|Zn) batteries by Garcia et al. [34] and Berchmans et al. [35]. Secondary LIB with printed electrodes have been demonstrated with up to 100 discharge/charge cycles 
by Ostfeld et al. [32] and Sousa et al. [36]. Kim et al. [25] present a fully printed secondary $\mathrm{Zn} \mid \mathrm{MnO}_{2}$ battery equipped with an ionic polymer gel electrolyte (PGE). While fabricated $\mathrm{Zn} \mid \mathrm{MnO}_{2}$ batteries completed more than 1,000 discharge/charge cycles without cell failure, capacity retention declined during the initial 100 cycles.

Though, the term "printed battery" is not clearly defined. The range of reported battery fabrication techniques, construction principles and encapsulation procedures seem to have no limits. Printed batteries may consist of printed electrode layers with the remaining battery components being realised by manual or semi-automatic pick and place technologies. Except for the substrate and encapsulation, all functional layers of printed batteries can be completely realised by printing technologies (Fig. 1a) [24, 25, 29, 37, 38]. For printed current collectors, commercially available conductive silver and carbon black inks are typically the first choice to meet the demanded requirement of an acceptable electrical conductivity to reduce the ohmic drop during discharge (Fig. 1d). Alternative current collector fabrication methods such as hot stamping of metal foils (Fig. 1b) or nickel-plating of previously etched copper layers (Fig. 1c) are being assessed with respect to their suitability but the benefits are yet unproven.

Conductive printing inks are modified by the suppliers with respect to viscosity, solids content, solid pigment type as well as particle size distribution and particle shape to match application-specific product requirements. Current collectors for printed batteries can be realised by printing or coating of silver layers [14, 20,39], printing of silver layers subsequently passivated by printing of carbon black layers [24, 27-29, 40, 41] or solely printing of carbon black layers [10, 21-23, 26, 30]. From an economic and materials science point of view, printing of carbon black current collectors is the preferred method. The existence of metallic silver inside the encapsulated battery is unfavourable when exposed to the mainly liquid or gel-like electrolytes. Power consuming parasitic side reactions at the surface can consequently damage current collectors causing self-discharge and finally malfunction of the battery. Therefore, electrochemical passivation of silver current collectors by protective carbon black layers with low surface areas is a common method to extend battery shelf-life and life cycle.

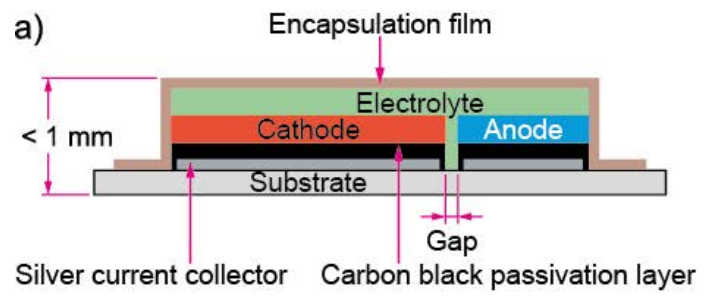

b)

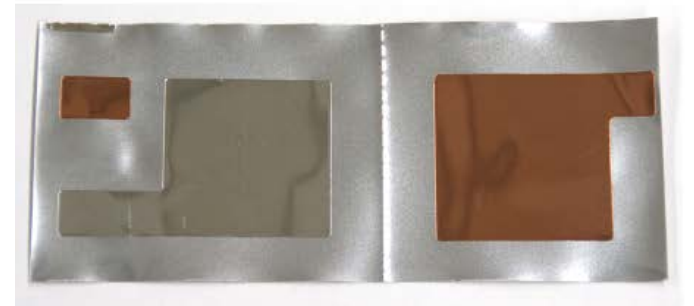

c)

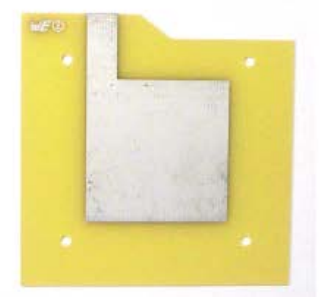

d)

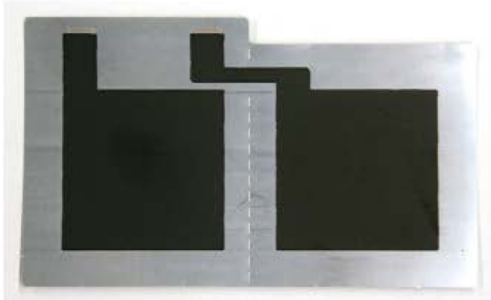

Fig. 1 (a) Cross-section drawing of the construction principle of a screen-printed battery in coplanar configuration; (b) current collectors fabricated by hot stamping of an aluminium and copper film on a flexible multi-layered high barrier substrate for screen-printed stack-type lithium-ion batteries; (c) non-flexible nickel-plated copper current collector on a fiberglass based FR4 printed circuit board (PCB) substrate material; (d) screen-printed silver current collectors passivated by a carbon black layer on a flexible three-layered high barrier substrate for printed $\mathrm{Ni} \mid \mathrm{MH}$ and $\mathrm{Zn} \mid \mathrm{MnO}_{2}$ battery applications in stack configuration

This study presents a systematic approach to determine the passivation capability of carbon black layers printed on top of metallic silver current collectors. Carbon black passivation layer fabrication is varied with respect to (i) the solids content of the selected screen printing inks, (ii) the printed layer thickness 
realised by modification of screen mesh parameters and (iii) adaptation of the printing method to a double print wet-on-dry. Printed $\mathrm{Zn} \mid \mathrm{MnO}_{2}$ batteries are predominantly powered by alkaline potassium hydroxide $\mathrm{KOH}$ or acidic zinc chloride $\mathrm{ZnCl}_{2}$ electrolytes. Therefore, passivation capability of printed carbon black layers with low surface areas is analysed qualitatively in these electrolyte environments by means of cyclic voltammetry (CV). A novel mathematical approach based on Faraday's law allows transformation of $\mathrm{CV}$ curve progressions to a quantitative comparison of the passivation capability of the carbon black layers prepared with different screen meshes, process techniques and printing inks. Scanning electrode microscopic (SEM) studies and energy-dispersive spectroscopy (EDS) measurements were conducted on processed samples of current collectors to identify the cause of the insufficient protective function.

\section{Materials and methods}

\subsection{Principles of cyclic voltammetry}

CV is performed in an electrochemical cell frequently consisting of a stationary three-electrode arrangement immersed in an ionic conductive electrolyte solution. The typical experimental setup consists of a working electrode (WE) where the reactions of interest occur, a reference electrode (RE), and a counter electrode (CE). The CE balances the charge-transfer processes at the WE by an electrontransfer of opposite direction. All electrodes are connected to a potentiostat which allows control of the potential of the WE with respect to the RE at the desired experimental conditions [42, 43]. During CV experiments, a linearly increasing and decreasing potential variation with a scan rate $v=|\mathrm{dE} / \mathrm{dt}|$ is imposed by the potentiotstat on the WE within a selected potential window between $E_{1}$ and $E_{2}$ (Fig. 2a). The current response to the potential variation is recorded (Fig. 2b). Plotting of the current $I$ as a function of the potential $E$ results in a current-potential plot: the cyclic voltammogram (Fig. 2c). The graphical depiction of voltammograms in this paper is based on the IUPAC convention with positive potentials being plotted to the right of the origin and anodic currents being positive [44-46].

The increase then decrease of the applied potential forces charge-transfer processes at the interface of the electrode and the electrolyte solution. Increase of the energy of the electrons can be realised by driving the WE to a negative potential. If a specific negative potential is exceeded, electrons may transfer from the WE into vacant electronic states on species of the electrolyte. In this case, an anodic current flow from the WE to the electrolyte solution is measured. In contrast to this, lowering of the energy of the electrons by driving the WE to a very positive potential can force charge-transfer from electrons on the solute to the WE. In this case, a cathodic current flow is measured (Fig. 2c). Due to the fixed potential of the RE, all charge-transfer processes in the electrochemical cell caused by electrochemical reactions can be attributed to the WE. The critical potentials at which these processes occur are related to the standard potentials $E^{0}$ for the specific chemical substances in the electrochemical system. These substances can be identified as local current peaks in the voltammogram. The shape characteristics of the CV curve in the anodic and cathodic areas provide useful information on all possible electrochemical reactions that can occur at the WE in the potential range of interest. Curve progressions can also provide information to identify capacitive or faradaic current flows [42, 47, 48]. 
a)

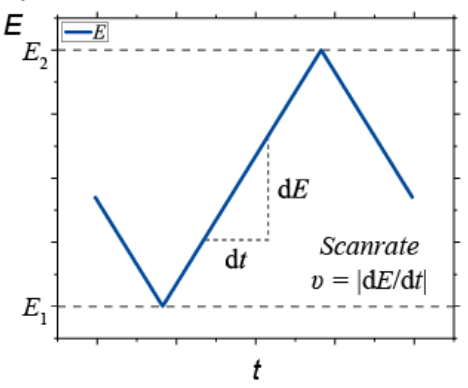

b)

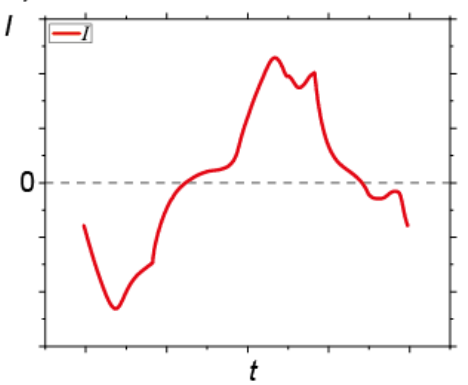

c)

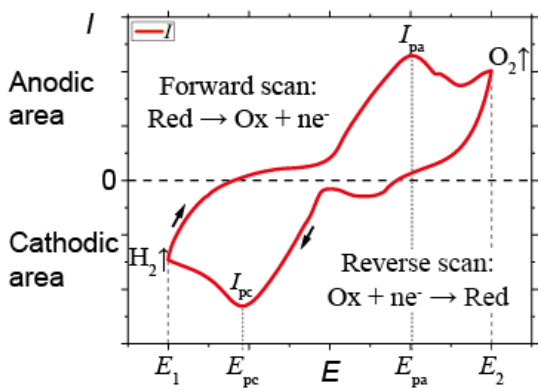

Fig. 2 (a) $E_{\mathrm{WE}}$ vs. $t$ plot of a cyclic voltammetry experiment with definition of the scan rate; (b) corresponding $I$ vs. $t$ plot; (c) exemplary plot of the $I$ vs. EWE curve (cyclic voltammogram) based on the data shown in (a) and (b) indicating charge-transfer processes and relevant experimental parameters

\subsection{Determination of the passivation capability of printed carbon black layers}

Charge-transfer reactions characterised by heterogeneous electron-transfer reactions are governed by Faraday's law. In this case, the number of electrons crossing the interface between the WE and the electrolyte solution is related stoichiometrically to the extent of the chemical reaction. Depending on the potential applied by the potentiostat, the electron-transfer reactions can result in oxidation or reduction processes of a chemical substance at the WE causing a faradaic current flow. The number of electrons transferred during the electrochemical reactions can be measured as the total charge $Q$ passed into the circuit $[42,43,49]$. Assuming an one-electron reaction and depending on the applied potential of the WE, the passage of a charge of 96,485.4 C through the external circuit causes either consumption of 1 mole of reactant or production of 1 mole of product at the surface of the WE. Charge-transfer reactions occurring at specific standard potentials $E^{0}$ can be inhibited by modification of the electrochemical cell or the experimental parameters. In case of surface passivation of a metallic WE material by a printed or coated carbon black layer, the additional potential needed to drive a reaction at a certain rate is attributed to the overpotential [42].

Current integration of the absolute areas under the CV curves allows determination of the amount of charge $Q$ transferred during the electrochemical reaction for each individually passivated silver working electrode $[42,48]$. According to the IUPAC convention, the anodic area of a CV curve is characterised by a positive current flow. Thus, possible oxidation processes of specific electrochemical reactions are forced to occur in the potential range of interest if not inhibited by an overpotential. As shown in Fig. 3, current integration of the absolute anodic areas of the $\mathrm{CV}$ curves at a specific cycle count allows calculation of the oxidation power $P_{\mathrm{Ox}}$ according to Equation 1 . When $P_{\mathrm{Ox}}$ is divided by the scan rate $v$ applied during the CV experiments, the related oxidation charge $Q_{\mathrm{Ox}}$ is received (Equation 2). 


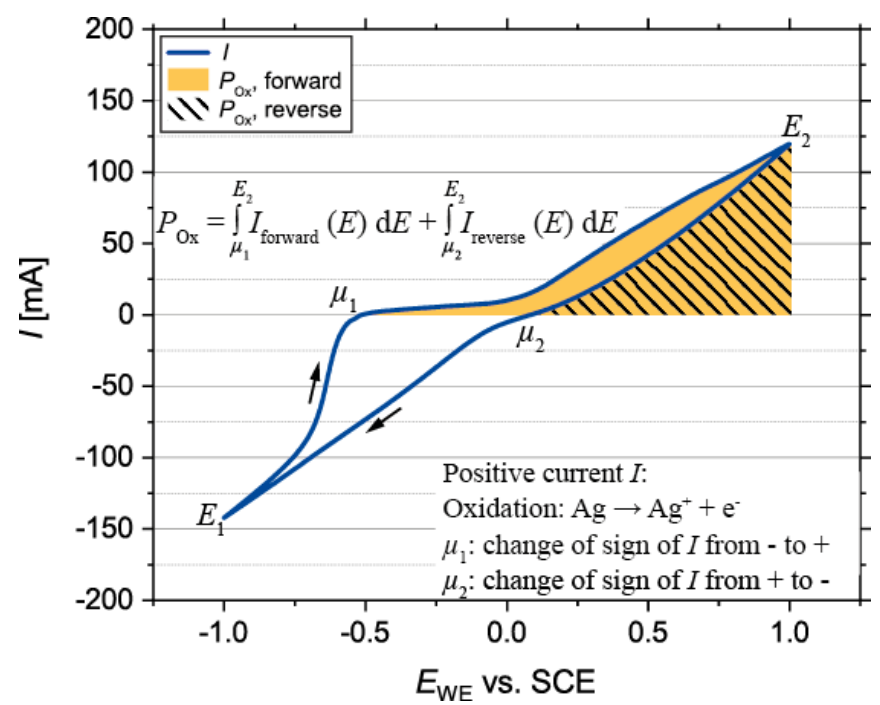

Fig. 3 Exemplary cyclic voltammogram indicating the absolute areas of anodic current integration to obtain the corresponding oxidation power $P_{\mathrm{Ox}}$ during the forward and reverse scan

$$
\begin{aligned}
P_{O x} & =\int_{\mu 1}^{E 2} I_{\text {forward }}(E) d E+\int_{\mu 2}^{E 2} I_{\text {reverse }}(E) d E \\
Q_{O x} & =\frac{P_{O x}}{v}
\end{aligned}
$$

If a faradaic current flow is related to charge-transfer by silver oxidation at the surface of the WE, Faraday's law of electrolysis enables recalculation of the absolute mass of silver oxidised $m_{\mathrm{Ag}, \mathrm{Ox}}$ during the specific cycle count by inserting $Q_{\mathrm{Ox}}$ instead of $Q$ (Equation 3).

$$
m_{A g, O x}=\frac{Q_{O x} \cdot M_{A g}}{F \cdot Z}
$$

With: $M_{\mathrm{Ag}}=107.9 \mathrm{~g} \mathrm{~mol}^{-1} ; F=96,485.3 \mathrm{C} \mathrm{mol}^{-1} ; z=1$.

Division of the value $m_{\mathrm{Ag}, \mathrm{Ox} \text {,sample }}$ of the WE that is passivated by an individually fabricated carbon black

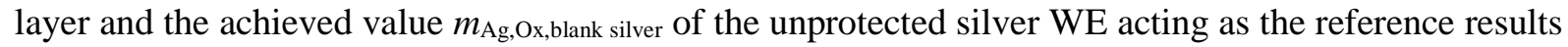
in the dimensionless value of the oxidation ratio $\theta_{\text {Ox }}$. As shown in Equation 4, $\theta_{\text {Ox }}$ describes the ratio of metallic silver that participated in electrochemical reactions despite the existence of a passivation layer. The overall quantity of metallic silver that can participate in electrochemical reactions of unprotected, non-passivated silver working electrodes under the specified conditions is taken as reference.

$$
\theta_{O x}=\frac{m_{A g, O x, \text { sample }}}{m_{\text {Ag,ox,blank silver }}}
$$

Equation 4 indicates decline of passivation capability after performing a certain count of cycles during $\mathrm{CV}$ experiments. In contrast, equation 5 provides information on the remaining passivation capability $\varphi$ of the passivation layers of each individual carbon black layer after completion of the electrochemical experiment.

$$
\varphi=\left(1-\theta_{O x}\right) \cdot 100 \%
$$

The existence of unknown parasitic side reactions slightly affecting current values within the electrochemical experiment cannot be excluded. Since all samples are tested under identical conditions, current values are expected to have an equal systematic error. 


\subsection{Electrochemical cell construction and experimental parameters}

Electrochemical experiments were conducted on a Bio-Logic SP-300 potentiostat (Bio-Logic Science Instruments, Seyssinet-Pariset, France) in a stationary three-electrode arrangement comprising of the working electrode (WE), the reference electrode (RE) and a counter electrode (CE) (Fig. 4a). For the RE, a Radiometer Analytical XR110 (Hach Company, Loveland, U.S.A.) saturated calomel electrode (SCE) with a saturated potassium chloride $\mathrm{KCl}$ electrolyte solution was selected. The SCE has a fixed potential of $-0.241 \mathrm{~V}$ versus the standard hydrogen electrode (SHE). A 80 mesh platinum gauze electrode from Bas Inc. (Tokyo, Japan) acted as the CE. The electrochemical cell was completed by immersion of the three electrodes in $250 \mathrm{ml}$ of previously prepared $6.0 \mathrm{M} \mathrm{KOH}(\mathrm{pH}>14)$ and $5.8 \mathrm{M}$ $\mathrm{ZnCl}_{2}$ (pH: 2.3) electrolyte solutions (Fig. 4b).

a)

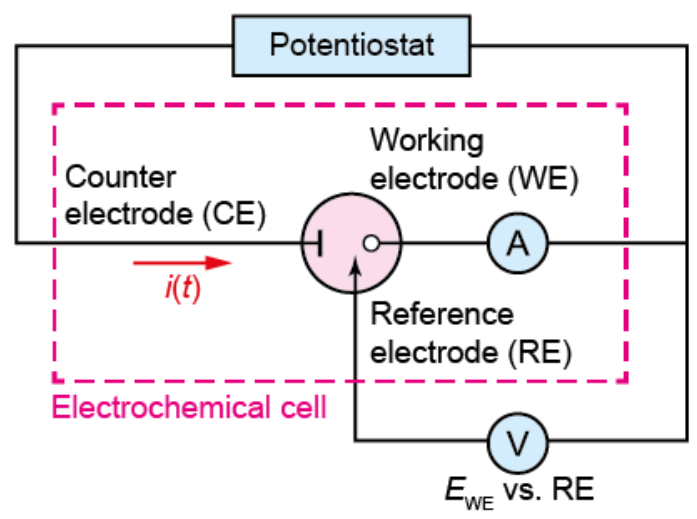

b)

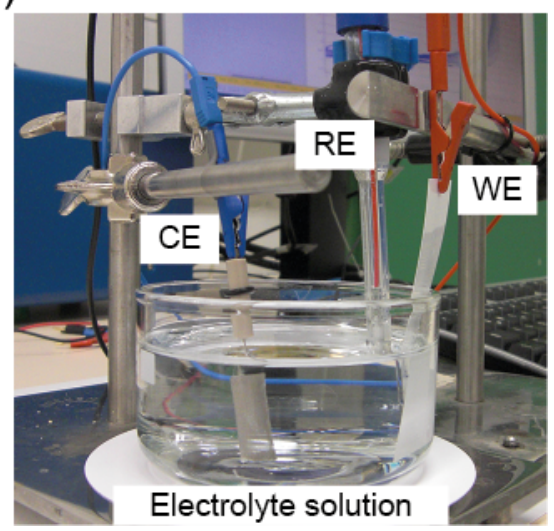

Fig. 4 (a) Circuit diagram of the electrochemical experiment in three-electrode arrangement; (b) experimental setup used for the CV measurements in this experimental series showing the stationary WE, RE and CE immersed in the electrolyte solution

The potential window for the characterisation of the passivation capability of printed WE samples was set between the vertex potentials $E_{1}=-1.0 \mathrm{~V}$ and $E_{2}=1.0 \mathrm{~V}$. Vertex potential values were selected to minimise the impact of hydrogen and oxygen formation by electrolytic decomposition of electrolyte solutions on current response. The voltage window was scanned with a scan rate of $v=1,000 \mathrm{mV} \mathrm{s}^{-1}$ to avoid diffusion of electrochemical active species from the bulk electrolyte solution to the WE surface. Reliable conclusions from CV curves on the passivation capability of printed carbon black layers were assured by recording 100 cycles of each tested WE sample. CV experiments were conducted at room temperature $\left(22^{\circ} \mathrm{C}\right)$ and the electrochemical cell was intentionally kept open to the ambient environment to simulate realistic conditions of the printed $\mathrm{Zn} \mid \mathrm{MnO}_{2}$ and $\mathrm{NiMH}$ battery fabrication process. Usually, printed or non-printed electrolyte layers are exposed temporarily to the ambient before encapsulation is performed.

\subsection{Working electrode preparation}

Screen-printed working electrodes consist of a square-shaped area connected by a terminal of $64 \mathrm{~mm}$ in length and $5 \mathrm{~mm}$ in width (Fig. 5). Carbon black passivation layers were designed to circumferentially overlap the area of the silver WE by $1.0 \mathrm{~mm}$. Protection of the carbon black passivated terminals of the WE towards electrochemical interaction during the CV experiments was assured by printing of UVcurable dielectric layers. Additionally, the accurate size of the geometrical area of the working electrodes was ensured by this procedure. 


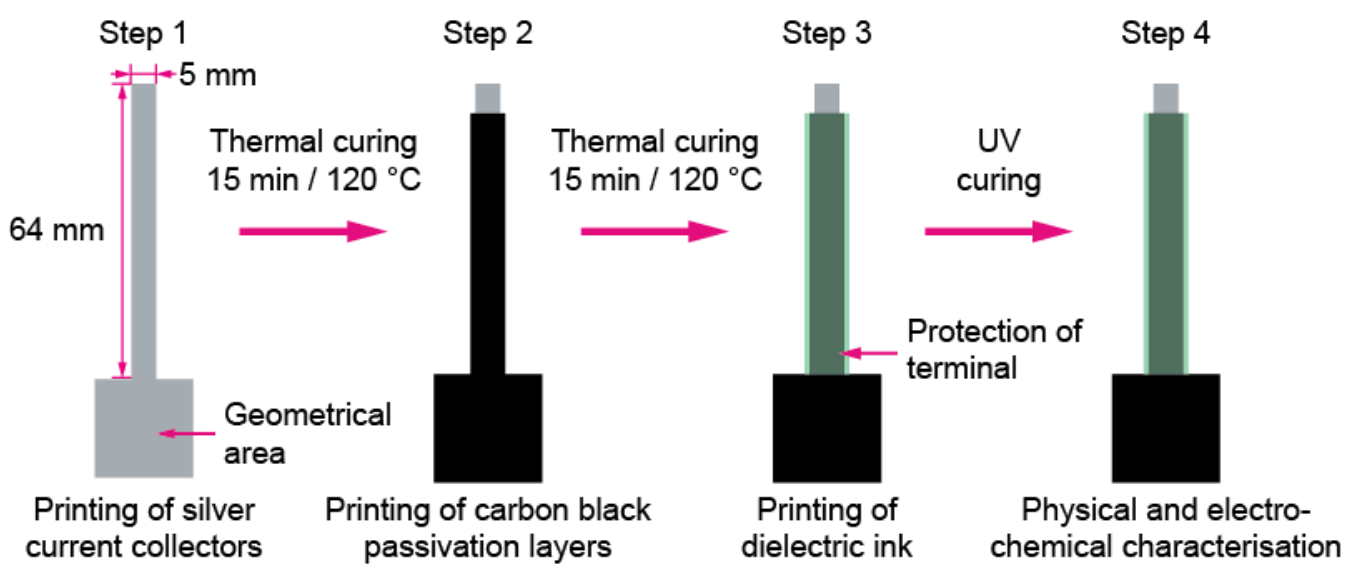

Fig. 5 Layout and processing steps of screen-printed silver working electrodes passivated with carbon black inks

Various types of printing inks can be processed by screen printing. Individually selected screen mesh parameters allow adaptation of the printing technique to specific printing ink characteristics (i.e. particle size) and printing product requirements (i.e. layer thickness) [9]. In this study, two screen mesh geometries provided by Sefar AG (Thal, Switzerland) were selected to achieve the desired layer thickness variation of printed carbon black passivation layers. Printing of passivation layers was realised with two conductive carbon black screen printing inks with different solids content (Table 1). Crucial printing process parameters were kept constant during the printing of both carbon black inks to avoid process induced fluctuations on layer thickness values. Table 1 provides detailed information on printing process parameters and WE sample identification of individually prepared carbon black passivation layers. In total, six configurations of working electrodes are available to be analysed by CV in both electrolyte solutions (Table 1).

Table 1 Processing parameters and sample identification of WE with individually prepared carbon black passivation layers

Processing and sample identification of printed passivation layers

\begin{tabular}{l|c|c|c}
$\begin{array}{l}\text { Carbon black } \\
\text { screen printing ink }\end{array}$ & $\begin{array}{c}\text { Single print stroke } \\
\text { Sefar PET1500 100-40 }\end{array}$ & $\begin{array}{c}\text { Double print wet-on-dry } \\
\text { Sefar PET1500 100-40 }\end{array}$ & $\begin{array}{c}\text { Single print stroke } \\
\text { Sefar PET1500 54-64 }\end{array}$ \\
\hline $\begin{array}{l}\text { Henkel Loctite } \\
\begin{array}{l}\text { Electrodag E\&C PF 407 C } \\
\text { Solids content: } \sim 40 \%\end{array}\end{array}$ & A1 & A1D \\
$\begin{array}{l}\text { Lackwerke Peters } \\
\text { SD 2842 HAL } \\
\text { Solids content: } \sim 80 \%\end{array}$ & B1 & B1D & B2 \\
$-\begin{array}{l}\text { Expected passivation } \\
\text { layer thickness }\end{array}$ & + & +++ & ++ \\
\hline
\end{tabular}

Detailed information on screen printing form preparation (section 1.1), physical and rheological parameters of conductive printing inks (section 1.2 respectively 1.4), and the printing experiments (section 1.3) is provided in the supplementary information.

Preliminary tests were performed to identify the effect of current evolution dependence on the geometrical area of the working electrodes (section 3.2.1). Therefore, WE with five geometrical areas were printed with a conductive silver ink: $100 \mathrm{~mm}^{2}, 150 \mathrm{~mm}^{2}, 200 \mathrm{~mm}^{2}, 300 \mathrm{~mm}^{2}$ and $500 \mathrm{~mm}^{2}$. For the main experiments presented in section 3.2.3, electrochemical passivation of previously printed silver layers was realised by printing of carbon black layers of different layer thicknesses (Table 1). 


\subsection{Microscopic studies and chemical analysis}

Characterisation of silver and carbon black passivation layer thicknesses of printed WE samples was performed with a Keyence VK-9700K colour 3D laser microscope (Keyence Corporation, Osaka, Japan). Scanning electrode microscopic (SEM) studies were conducted on printed WE samples for the characterisation of the surface morphology and to identify possible pinholes in the carbon black passivation layers subsequently to the $\mathrm{CV}$ measurements. To improve the image contrast, thin layers of gold were deposited on the surfaces of the WE with a Cressington 108 manual sputter coater (Cressington, Watford, United Kingdom). The samples were then analysed with a Tescan Vega 3 SEM using the scanning electron (SE) detector (Tescan GmbH, Dortmund, Germany).

For analysis of the elemental and chemical composition of surface measuring spots of selected WE samples, energy-dispersive spectroscopy (EDS) measurements were performed with a Jeol 6300 F SEM (Jeol Inc., Peabody, U.S.A.) equipped with an Oxford/Link Pentafet eXL-10 EDS X-ray Si detector (Oxford Instruments, Abingdon, United Kindom). EDS analysis was performed in ultra-thin window (UTW) mode after only a few atomic layers' thick graphite layer was deposited on the surface of the WE samples in an Emscope SC500 sputter coater under a nitrogen atmosphere. 


\section{Results and discussion}

\subsection{Physical characterisation of printed working electrodes}

Printing of the Henkel PF 050 silver ink resulted in an average dry layer thickness of (10.0 \pm 1.1$) \mu \mathrm{m}$ on the $175 \mu \mathrm{m}$ thick polyethylene terephthalate (PET) substrate. Fig. 6a shows the results of dry layer thickness measurements of individually printed carbon black passivation layers on top of printed silver layers. Essential differences are visible for dry layer thickness values of passivation layers prepared with the Henkel PF 407 C (A) ink and the Lackwerke Peters SD 2842 HAL (B) ink. A single print stroke of the PF 407 C ink with the fine 100-40 screen mesh resulted in an average carbon black passivation layer thickness of $6.0 \mu \mathrm{m}$ (A1). Though, a subsequently performed double print with the wet-on-dry technique did not result in doubled layer thickness values. In this case, increase of the average carbon black layer thickness by around $50 \%$ to $9.2 \mu \mathrm{m}$ was determined for the samples A1D. Printing of the PF $407 \mathrm{C}$ ink with a coarse 54-64 screen mesh with a single print stroke (A2) leads to an increase in average layer thickness by only $1.7 \mu \mathrm{m}$ compared to layer thicknesses printed with the fine 100-40 screen mesh (A1). Carbon black dry weight mass values correlate with obtained layer thickness values and range from $2.4 \mathrm{~g}$ (A1) to $4.7 \mathrm{~g}$ (A1D) received with a double print wet-on-dry.

a)

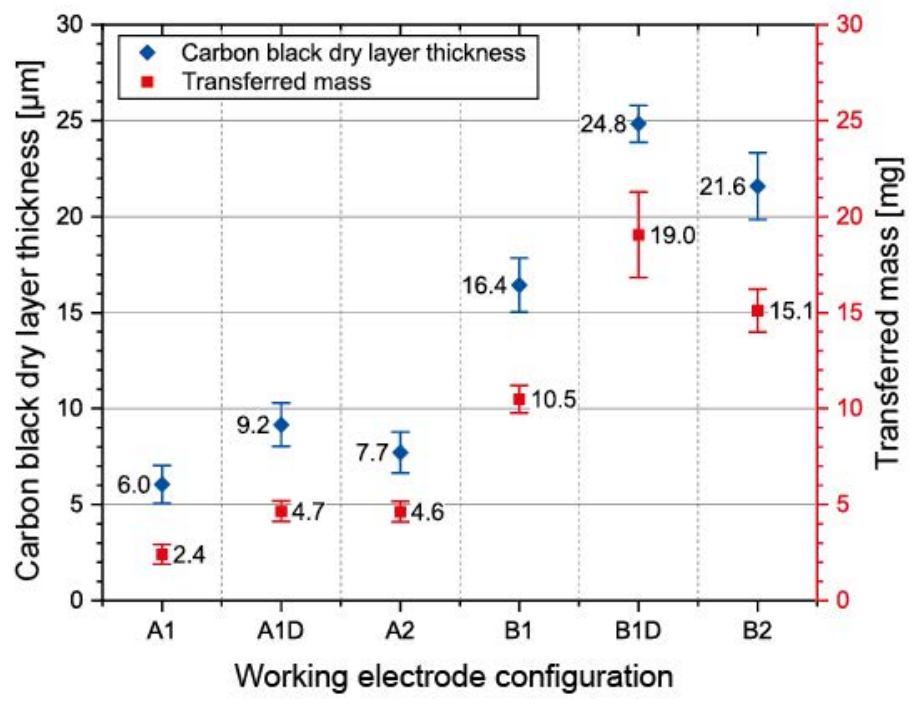

b)

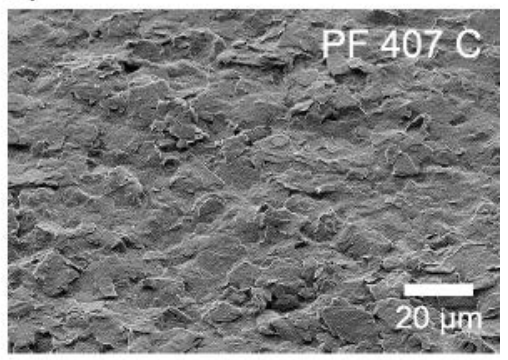

c)

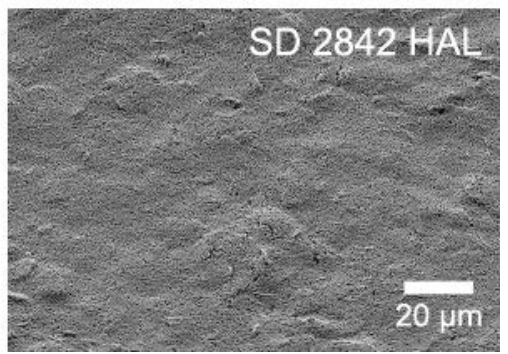

Fig. 6 (a) Plot of determined dry passivation layer thicknesses and transferred dry masses of carbon black on silver WE with $300 \mathrm{~mm}^{2}$ geometrical area; (b) SEM image of a printed PF $407 \mathrm{C}$ passivation layer A1D; (c) SEM image of a printed SD 2842 HAL passivation layer B1D. SEM images were recorded at a magnification of $2 \mathrm{kx}$

Increase of the average passivation layer thickness values is clearly visible for silver layers passivated with the SD 2842 HAL ink. While a single print stroke with the fine 100-40 screen mesh provided $16.4 \mu \mathrm{m}$ (B1) thick passivation layers on top of the silver, an additional printing step wet-on-dry raised this value by $50 \%$ to $24.8 \mu \mathrm{m}$ (B1D). Working electrode samples of the series B2 printed with the coarse 54-64 mesh consisted of an average passivation layer thickness of $21.6 \mu \mathrm{m}$. These results are reflected by elevated dry weight masses of the passivation layers (Fig. 6a). Compared to the passivation layers printed with the PF $407 \mathrm{C}$ ink, values for the samples B1 and B1D were quadrupled while the mass of $\mathrm{B} 2$ is nearly equivalent to three times the mass of $\mathrm{A} 2$.

In general, printed passivation layer thickness and dry weight masses are predominantly affected by the solids content of the respective carbon black ink. Concerning the relation between the thickness of the protective layer and its passivation capability, extended durability is expected for WE samples of series B passivated with the SD 2842 HAL ink. Furthermore, raw material related differences were found in surface characteristics of passivation layers realised with both carbon black printing inks. While carbon black flakes of the PF 407 C ink are clearly visible (Fig. 6b), a smooth surface is obtained by printing 
of the SD $2842 \mathrm{HAL}$ ink (Fig. 6c). In contrast to electrodes traditionally consisting of high surface area activated carbons $\left(\sim 3,000 \mathrm{~m}^{2} \mathrm{~g}^{-1}\right)$ for i.e. supercapacitors [50, 51], printed carbon black layers fabricated in this study exhibit very low surface areas in the range of $1.5 \mathrm{~m}^{2} \mathrm{~g}^{-1}$. Binding agents and other printing ink additives clog the porous structure of dissolved carbon particles resulting in mechanically stable carbon black layers with marginal capacitances [52]. In consequence, the protective functionality of the printed carbon black layers is the focus of this research study.

\subsection{Cyclic voltammetry experiments}

\subsubsection{Effect of working electrode material and geometrical area}

Unprotected silver working electrodes and PF $407 \mathrm{C}$ carbon black WE with varying sizes of geometrical area were analysed in $6.0 \mathrm{M} \mathrm{KOH}$ and $5.8 \mathrm{M} \mathrm{ZnCl}_{2}$ aqueous electrolyte solutions including the experimental parameters described in section 2.3. For each tested WE sample, 100 cycles were recorded in the potential range of $-1.0 \mathrm{~V}$ and $1.0 \mathrm{~V}$. The last loop of each sample was then plotted to obtain further information on current response and the current dependency to the size of the apparent electroactive area.

Asymmetric loops of the silver working electrodes with geometrical areas in the range of $100-500 \mathrm{~mm}^{2}$ analysed in $6.0 \mathrm{M} \mathrm{KOH}$ and $5.8 \mathrm{M} \mathrm{ZnCl}_{2}$ aqueous electrolyte solutions are presented in Fig. 7a respectively Fig. 7b. In Fig. 7a, analysed in an alkaline electrolyte environment, the oxidation of silver to silver oxide $\left(\mathrm{Ag}_{2} \mathrm{O}\right)$ driven by charge release during the forward scans can be assumed by the sharp increases in anodic currents ranging from $75 \mathrm{~mA}\left(100 \mathrm{~mm}^{2}\right)$ to around $160 \mathrm{~mA}\left(500 \mathrm{~mm}^{2}\right)$. The steady raise of current values can be explained by progressive surface extension with an increased amount of silver being available to oxidation reactions occurring at the surface of the WE. During the reverse scan, the potential of the WE is lowered and the amount of oxidised species is reduced. The reciprocally proportional decline of reduction of oxidised species to increasing electroactive areas can be explained by detachment of $\mathrm{Ag}_{2} \mathrm{O}$ from the surface of the WE into the electrolyte solution thus not being available for reduction during the reverse scan.

In contrast, irreversible electrochemical reactions are illustrated by the loops of silver WE analysed in $5.8 \mathrm{M} \mathrm{ZnCl}_{2}$ electrolyte solution (Fig. 7b). As before, current increase in conformity with the extension of the printed electrode areas is observed. The maximum anodic current of around $100 \mathrm{~mA}$ is determined for the WE with a surface of $500 \mathrm{~mm}^{2}$. During the forward scan, all plotted loops comprise a characteristic current peak in the range of $0.5-0.6 \mathrm{~V}$ vs. SCE. Conversion of these values to the potential of the SHE reveals the standard potential $E^{0}$ for charge release by oxidation of silver (Equation 6) [53].

$A g \rightleftharpoons A g^{+}+e^{-}$

However, the absence of significant reduction related currents is noticeable. Local formation and precipitation of $\mathrm{ZnO}$ and $\mathrm{AgCl}$ into the electrolyte solution could be one explanation for the reduced amount of oxidised species being available for reduction at the surface of the WE during the reverse scan.

The voltammograms of the PF $407 \mathrm{C}$ carbon black WE analysed in $6.0 \mathrm{M} \mathrm{KOH} \mathrm{(Fig.} \mathrm{7c)} \mathrm{and} 5.8 \mathrm{M}$ $\mathrm{ZnCl}_{2}$ electrolyte solution (Fig. $7 \mathrm{~d}$ ) indicate significant changes inside the electrochemical cell. Both voltammograms demonstrate an increase of geometrical area correlating with an increase of anodic and cathodic currents located in the $\mu$ A-range. Fig. 7c provides information of carbon black electrodes analysed in the alkaline electrolyte environment. The voltammogram shows narrow point-symmetric loops which are characteristic for supercapacitors with large contact resistance analysed at high scan rates [50,54]. Diminishing rectangular-like shapes can furthermore be related to a decline in capacitive behaviour which can be explained by the low porosity of the printed carbon black layers due to binding agents filling the porous structure of the carbon black particles inside the printing inks. The loops of the voltammogram presented in Fig. 7d show a nearly similar behaviour although these carbon black WE were analysed in a $5.8 \mathrm{M} \mathrm{ZnCl}_{2}$ electrolyte solution. Small capacitive currents were recorded in the $\mu \mathrm{A}$ - 
range. Voltammograms indicate no characteristic current peaks in the scanned voltage window and confirm the capacitive behaviour of the carbon black WE in both electrolyte solutions.

a)

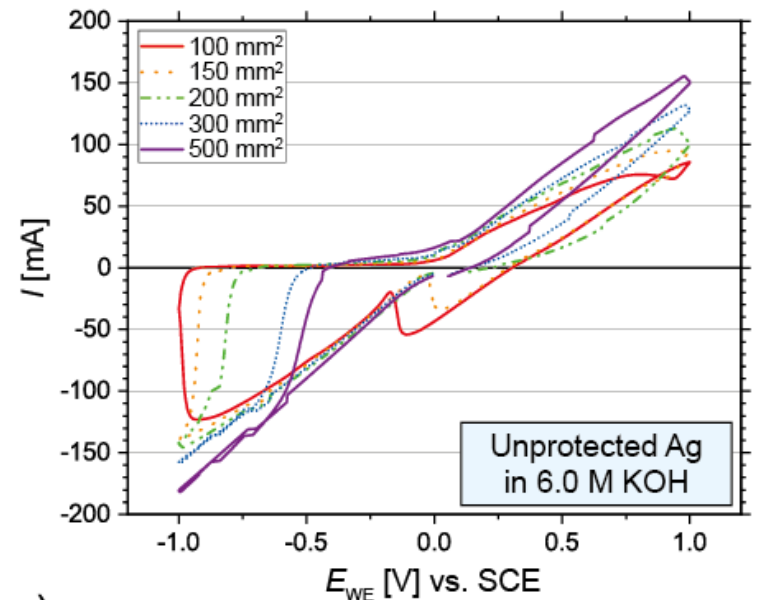

c)

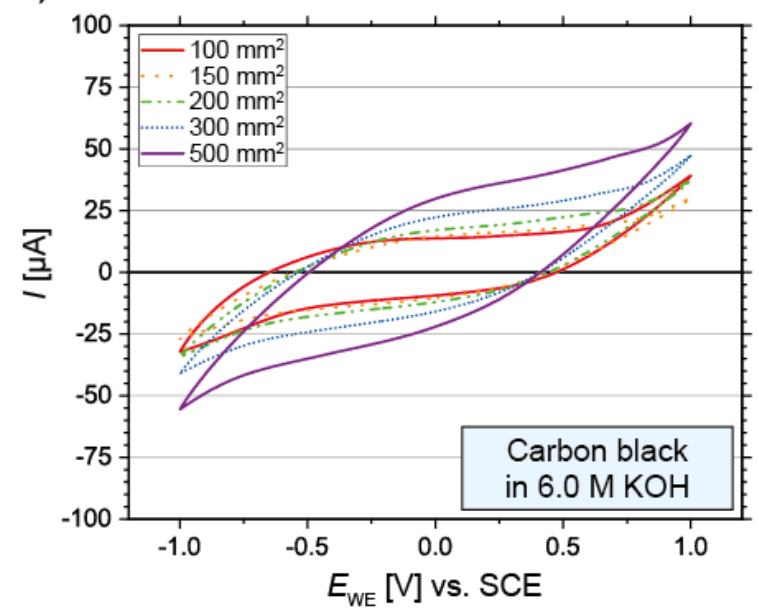

b)

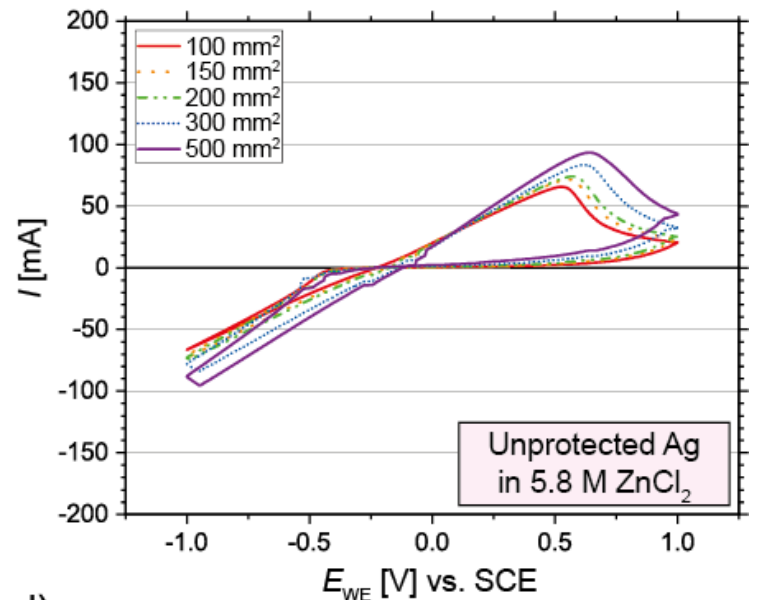

d)

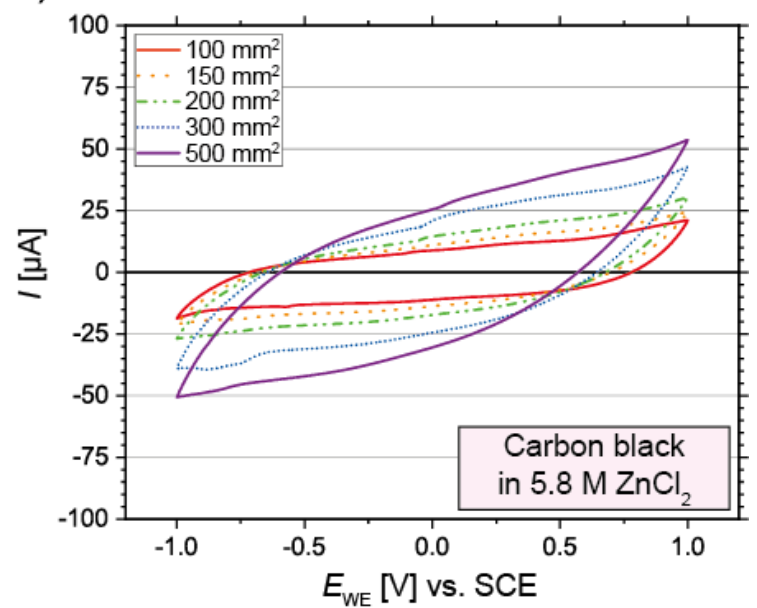

Fig. 7 Cyclic voltammetry plots of silver WE of geometrical areas of 100, 150, 200, 300 and $500 \mathrm{~mm}^{2}$ after 100 cycles in (a) 6.0 M KOH and (b) $5.8 \mathrm{M} \mathrm{ZnCl}_{2}$ aqueous electrolyte solutions. CV plots of bare carbon black (PF $407 \mathrm{C}$ ) WE with different geometrical areas after 100 cycles in (c) $6.0 \mathrm{M} \mathrm{KOH}$ and (d) $5.8 \mathrm{M} \mathrm{ZnCl}_{2}$ electrolyte solutions

\subsubsection{Definition of limiting conditions}

Based on the loops shown in the voltammograms in Fig. 7a-d, oxidation charges Qox were calculated according to the approach presented in section 2.2 to identify limiting conditions of the CV experiments. These limiting conditions enable the estimation of passivation capabilities of carbon black passivated silver layers.

The scatterplot in Fig. 8a shows average $Q_{O x}$ values in the mC-range from three independent measurements for the unprotected silver WE examined in both aqueous electrolyte solutions. The extended electrochemical interaction of silver with the $\mathrm{KOH}$ electrolyte is reflected by increased values of $Q_{\text {Ox }}$ compared to the values obtained in the $\mathrm{ZnCl}_{2}$ electrolyte. With $94.5 \%\left(\mathrm{ZnCl}_{2}\right)$ and $98.2 \%$ $(\mathrm{KOH})$, the coefficients of determination (COD) $R^{2}$ demonstrate a strong relationship between the size of the geometrical WE area and the values of calculated Qox. SEM studies of printed PF 050 silver layers provide evidence on the surface modification and extension by oxidation and reduction reactions during the electrochemical experiments in the respective electrolyte solution. SEM images were taken before CV (Fig. 8c), after performing 100 cycles in $6.0 \mathrm{M} \mathrm{KOH} \mathrm{(Fig.} \mathrm{8d),} \mathrm{and} \mathrm{after} \mathrm{performing} 100$ cycles in $5.8 \mathrm{M} \mathrm{ZnCl}_{2}$ electrolyte solution (Fig. 8e). Fig. 8c shows originally printed silver flakes with sharp edges while Fig. 8d indicates corrosion at the surface and edges of the silver flakes. The morphology of the silver WE presented in Fig. 8e suggests a local oxide formation on top of the silver flakes. 
The results of the calculation of $Q_{\text {Ox }}$ for the carbon black WE analysed in both electrolyte solutions from three independent measurements are illustrated in Fig. 8b. In contrast to the silver WE, the lower values of $Q_{\text {ox }}$ arranged in the $\mu C$-range are clearly recognisable. Although, increased values of $Q_{\text {ox }}$ are in line with an enlargement of the geometrical area. The slight difference between the calculated values of $Q_{0 x}$ analysed in both electrolyte solutions result in a close and nearly parallel progression of both linear regression lines. These results suggest a nearly identical capacitive behaviour of carbon black WE without electrochemical interaction of carbon black in both electrolyte solutions.

a)

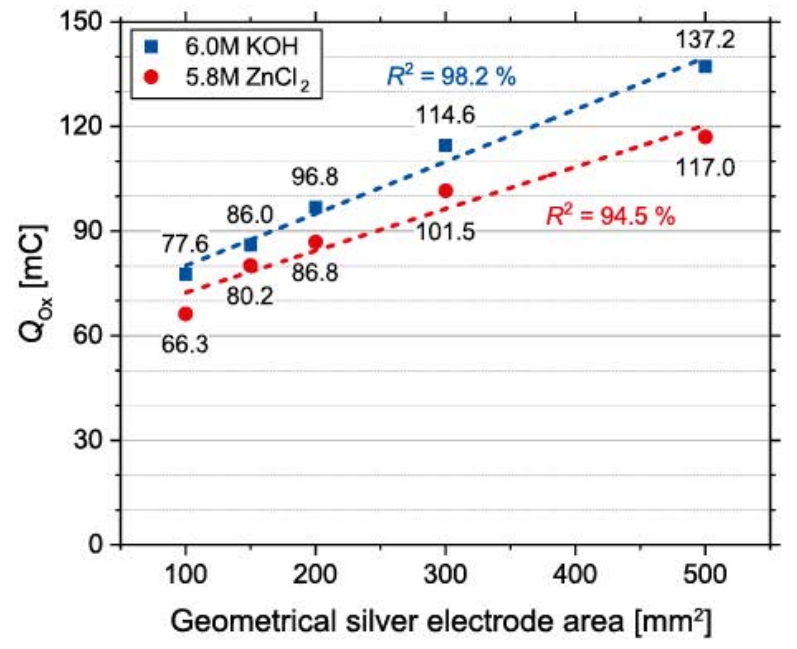

c)

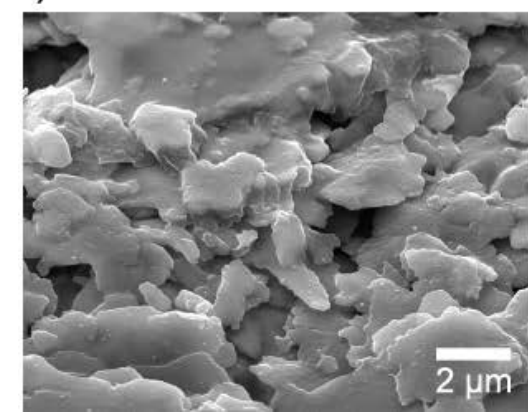

b)

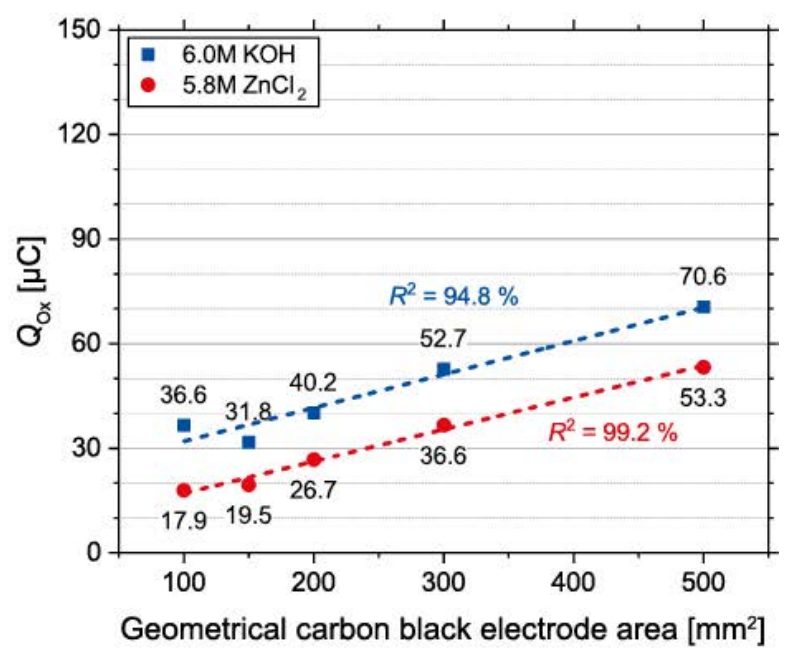

e)

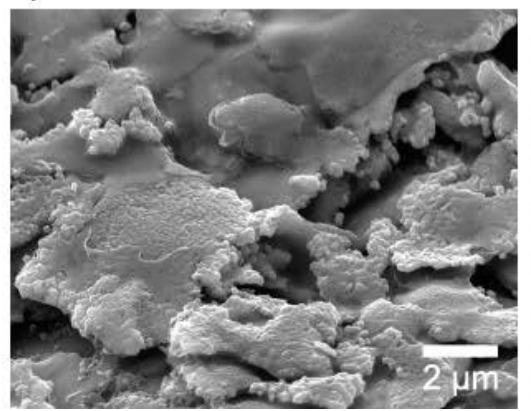

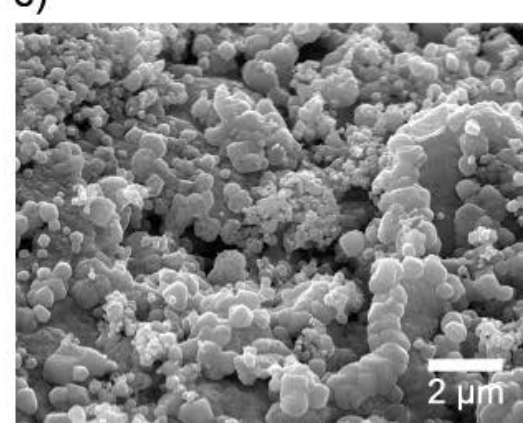

Fig. 8 (a, b) Scatterplots of averaged oxidation charges $(n=3)$ over geometrical WE area with linear regression lines for $(a)$ silver WE and (b) carbon black (PF $407 \mathrm{C}$ ) WE analysed in $6.0 \mathrm{M} \mathrm{KOH}$ and $5.8 \mathrm{M} \mathrm{ZnCl}_{2}$ electrolyte solutions. (c, d, e) SEM images recorded with an acceleration voltage of $20 \mathrm{kV}$ at a magnification of $20 \mathrm{kx}$ of (c) a printed PF 050 silver layer before being analysed by cyclic voltammetry and after 100 cycles performed in (d) $6.0 \mathrm{M} \mathrm{KOH}$ and (e) $5.8 \mathrm{M} \mathrm{ZnCl}_{2}$ electrolyte solutions

Concerning electrochemical analysis of silver working electrodes passivated by carbon black layers, it can be assumed that non-defective passivation layers generate $Q_{\mathrm{Ox}}$ values comparable to the bare carbon black WE when being analysed under identical conditions by CV. Specific increase of current values within the scanned potential window could then be ascribed to individual defects in the passivation layers with small silver spots being accessible for electrochemical interaction with the electrolyte solutions. This context enables the set up of a minimum limit (offset) for carbon black related capacitive currents and an upper limit (maximum) for oxidation reaction related faradaic currents occurring at unprotected silver layers. Partially damaged carbon black passivation layers must be arranged between those two limits. Passivation layers with low levels of damage are assumed to be located near the lower limit and vice versa.

Conditioned by the penetration properties of the $\mathrm{KOH}$ electrolyte, a possible falsification of the calculated oxidation charge values by an extension of the electroactive area at the edges of the WE cannot be excluded. The parallel but elevated progression of both blue dashed regression lines drawn for the WE samples examined in the $\mathrm{KOH}$ electrolyte is a prime indication of this (Fig. 8a, b). Since the 
edge-related effect of surface extension is increased by smaller geometrical areas (Equation 7), the geometrical area of the silver WE was set to $300 \mathrm{~mm}^{2}$ for the examination and evaluation of carbon black passivated silver WE presented in section 3.2.3 and 3.3.

$$
\lim _{a \rightarrow 0} \frac{\text { edge }}{\text { area }}=\lim _{a \rightarrow 0} \frac{4 a}{a^{2}}=\lim _{a \rightarrow 0} \frac{4}{a} \rightarrow \infty
$$

\subsubsection{Carbon black passivated silver working electrodes}

Fig. 9a-d shows cyclic voltammograms of the individually printed carbon black passivation layers on top of the silver working electrodes after completion of 100 cycles. CV experiments were conducted in 6.0 $\mathrm{M} \mathrm{KOH}$ and 5.8 $\mathrm{M} \mathrm{ZnCl}_{2}$ electrolyte solutions using the parameters described in section 2.3.

Fig. 9a provides information on the durability of carbon black layers printed with the PF $407 \mathrm{C}$ ink with a solids content of around $40 \%$ in the alkaline $\mathrm{KOH}$ electrolyte. Tracing of the red dash-dotted loop of sample A1 during the forward scan reveals a characteristic silver peak at $0.5 \mathrm{~V}$ vs. SCE. The silver oxidation reaction related maximum anodic peak current of $28 \mathrm{~mA}$ indicates a damage of the carbon black passivation layer which exhibited an average thickness of $6.0 \mu \mathrm{m}$ (Fig. 6a). During the reverse scan, the oxidised species is reduced to a virtually identical amount constituted by a nearly pointsymmetric progression of the complete voltammogram. The forward scan of the green loop of sample A2 indicates an extended passivation capability with a reduced anodic peak current of $7.6 \mathrm{~mA}$ at around $0.5 \mathrm{~V}$ vs. SCE followed by another peak at the vertex potential $E_{2}$ with around $15 \mathrm{~mA}$. The second current peak emerging at $E_{2}$ can be attributed to an incipient oxygen formation at the surface of the WE. An anodic peak current of only $1.5 \mathrm{~mA}$ was measured at the potential of $0.5 \mathrm{~V}$ indicating an almost defect-free passivation layer on top of the silver. In general, the increasing average passivation layer thicknesses of the samples A1 $(6.0 \mu \mathrm{m})$, A2 $(7.7 \mu \mathrm{m})$ and A1D $(9.2 \mu \mathrm{m})$ correspond nearly inversely proportional to the level of anodic currents recorded during the CV experiments. This can also be explained by higher sheet resistance values $R_{\square}$ dominated by the respective carbon black layer thickness.

Fig. 9b presents loops of WE samples $\mathrm{A} 1, \mathrm{~A} 2$ and $\mathrm{A} 1 \mathrm{D}$ recorded in an acidic $\mathrm{ZnCl}_{2}$ electrolyte environment. The red dash-dotted loop of sample A1 shows anodic and cathodic peak currents of $9.4 \mathrm{~mA}$ and $-13.0 \mathrm{~mA}$ being located at $0.05 \mathrm{~V}$ vs. SCE respectively $-0.45 \mathrm{~V}$ vs. SCE. While the latter value suggests reduction of $\mathrm{Ag}_{2} \mathrm{O}$ to $\mathrm{Ag}$, the shift of the anodic current peak indicates an interaction of $\mathrm{Ag}$ with the $\mathrm{ZnCl}_{2}$ electrolyte at the surface of the WE at an early stage. Due to the missing point-symmetry of the voltammogram, partly irreversible reactions can be assumed. The green loop of sample A2 confirms the previously made observation of an enhanced passivation capability realised by an increased carbon black layer thickness. Due to the improved protection of the silver layers, anodic and cathodic peak current values are limited to $0.4 \mathrm{~mA}$ and $-0.6 \mathrm{~mA}$. Further decrease of anodic $(0.11 \mathrm{~mA})$ and cathodic ( $-0.18 \mathrm{~mA})$ peak current values is realised with the sample A1D consisting of a double printed passivation layer (9.2 $\mu \mathrm{m}$ thick). In contrast to the alkaline $\mathrm{KOH}$ electrolyte environment, the interaction of possible silver spots caused by pinholes is generally decreased by limitation of the maximum current values recorded during the experiments in the $\mathrm{ZnCl}_{2}$ electrolyte. 
a)
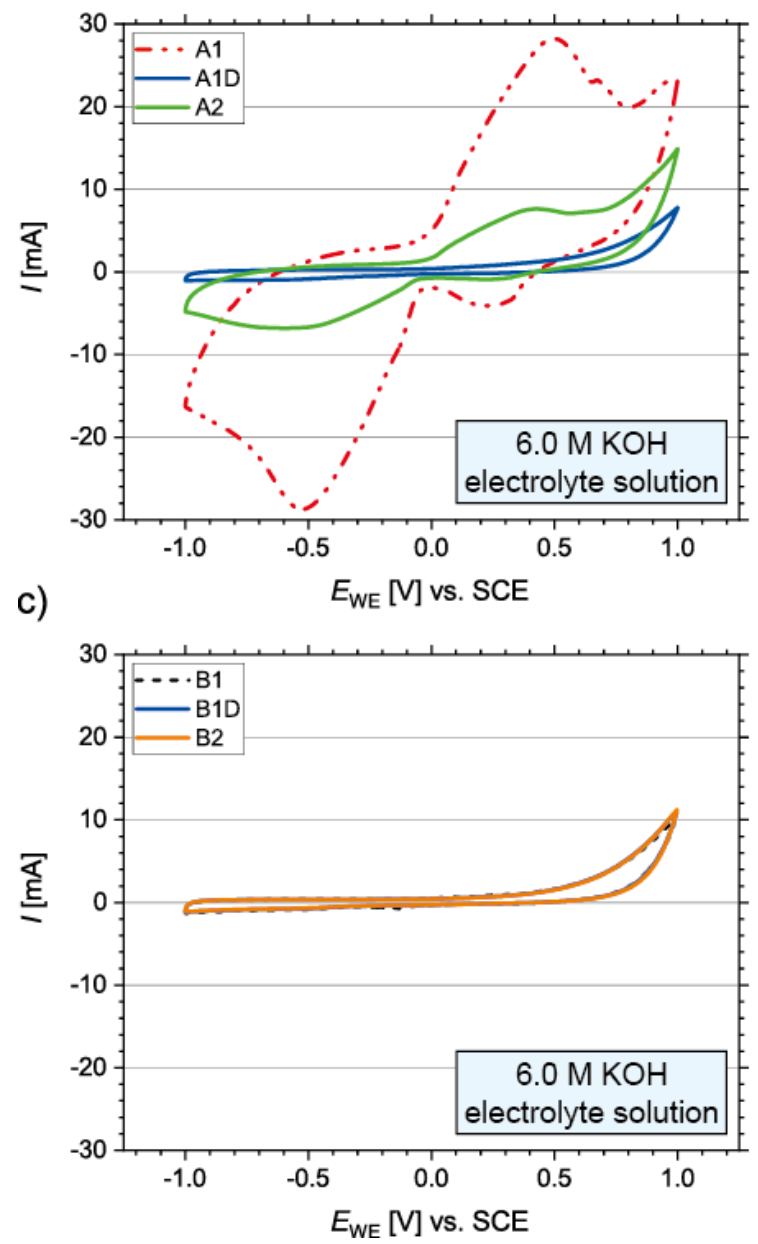

b)
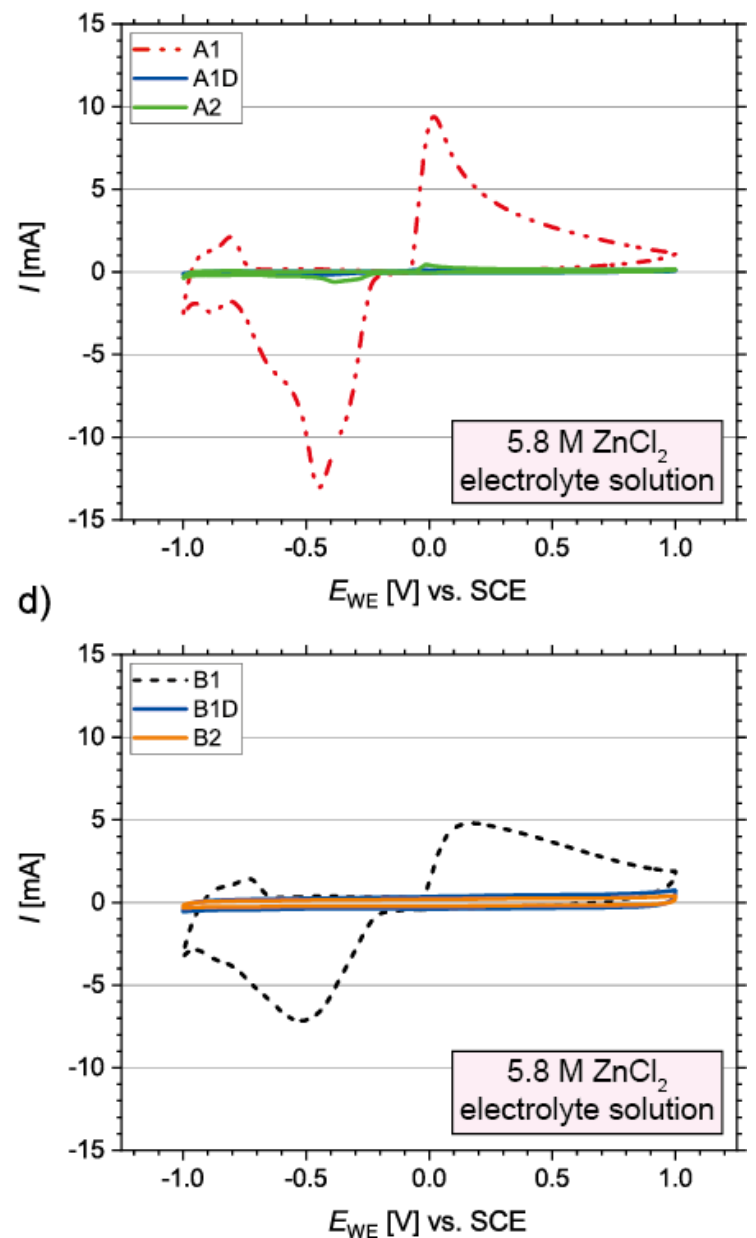

Fig. 9 Cyclic voltammograms of carbon black passivated silver working electrodes with $300 \mathrm{~mm}^{2}$ geometrical area after performing 100 cycles in (a, c) $6.0 \mathrm{M} \mathrm{KOH}$ and (b, d) in $5.8 \mathrm{M} \mathrm{ZnCl}_{2}$ aqueous electrolyte solutions

Cyclic voltammograms of silver layers passivated by printed layers of the SD $2842 \mathrm{HAL}$ carbon black ink (solids content $~ 80 \%$ ) are presented in Fig. 9c $(\mathrm{KOH})$ and Fig. 9d $\left(\mathrm{ZnCl}_{2}\right)$. The almost congruent loops of all samples B1, B2 and B1D illustrated in Fig. 9c exhibit expanded overpotentials without silver related current peaks within the scanned potential window. Thus, equivalent passivation capabilities can be assumed for the differently printed carbon black layers. However, all loops feature sharp current increases in the range of $10 \mathrm{~mA}$ close to the vertex potential $E_{2}$. These current increases can be attributed to an emerging oxygen formation. Peaks are promptly eliminated at the beginning of the reverse scans after passage of $E_{2}$.

Loops of the samples B1, B2, and B1D analysed in the $5.8 \mathrm{M} \mathrm{ZnCl}_{2}$ electrolyte solution are presented by the voltammograms of Fig. 9d. Except for the reduced values of the anodic and cathodic peak currents with $4.8 \mathrm{~mA}$ at $0.18 \mathrm{~V}$ vs. SCE and $-7.2 \mathrm{~mA}$ achieved at $-0.5 \mathrm{~V}$ vs. SCE, the black dotted line of sample A1 shows a nearly similar progression compared to the previously discussed sample A1 which has also been analysed in $\mathrm{ZnCl}_{2}$ (Fig. 9b). On the contrary, the samples B2 and B1D show large overpotentials in the potential window of interest without any occurrence of specific current peaks. Maximum current values for the anodic area are limited to $0.75 \mathrm{~mA}$ (B1D) and $0.4 \mathrm{~mA}$ (B2) at the vertex potential $E_{2}$. When compared to the loops in Fig. 9c, the absence of oxygen formation related current peaks is clearly visible. An overall expansion of passivation capability in the alkaline electrolyte environment is observed for WE samples passivated with a carbon black layer printed with the SD 2842 HAL ink. Increased average passivation layer thicknesses of the samples B1 $(16.4 \mu \mathrm{m}), \mathrm{B} 2(21.6 \mu \mathrm{m})$ and B1D $(24.8 \mu \mathrm{m})$ seem to be responsible for extended overpotentials. However, anodic and cathodic current 
peaks observed for the sample B1 in both electrolyte solutions are attributable to inhomogeneities or pinholes in the passivation layers.

\subsection{Evaluation of carbon black passivation capability}

According to the theoretical approach described in section 2.2, current integration was performed for the anodic areas of the loops plotted in the voltammograms shown in Fig. 9a-d to obtain corresponding $Q_{\text {ox }}$ values. Limiting conditions for this experimental series were determined in section 3.2.2. Therefore, current integration was additionally performed for both carbon black WE (A, B) and for the unprotected silver WE (Ag) acting as the reference.

Table 2 provides a summary of relevant parameters obtained by current integration of the anodic areas of analysed WE after performing 100 cycles in the respective aqueous electrolyte solution. Oxidation charge values $Q_{\mathrm{Ox}}$ of $114 \mathrm{mC}$ and $141 \mathrm{mC}$ were determined for the unprotected silver WE in $6.0 \mathrm{M} \mathrm{KOH}$ respectively 5.8 $\mathrm{M} \mathrm{ZnCl}_{2}$ electrolyte solution. Acting as the reference, absolute masses of oxidised silver $m_{\mathrm{Ag}, \text { Ox,blank silver }}$ during the 100th cycle were calculated according to Equation 3. Finally, calculation of the oxidation ratio $\theta_{\mathrm{Ox}}$ (Equation 4) enables estimation of the remaining passivation capability $\varphi$ of each individually prepared carbon black layer (Equation 5).

In accordance with curve progressions of the CV loops shown in Fig. 9a, the WE samples A1 and A2 analysed in the $6.0 \mathrm{M} \mathrm{KOH}$ electrolyte solution indicate the highest values of $Q_{\mathrm{Ox}}$ of this experimental series. Consequently, the remaining passivation capability $\varphi$ of fabricated carbon black layers is reduced to $77.5 \%$ (A1) and $91.5 \%$ (A2). Constant but slightly reduced values of the passivation capability were calculated for the WE samples B1, B1D and B2 analysed in the $\mathrm{KOH}$ electrolyte. The remaining passivation capability of these samples with around $96 \%$ is confirmed by the congruent progression of the respective CV loops illustrated in Fig. 9c. However, it must be pointed out here that the slight anodic current peaks which are attributed to an emerging oxygen formation may affect calculation of $Q_{\mathrm{Ox}}$ for these three samples.

Table 2 Summary of relevant parameters obtained by integration of anodic currents of analysed working electrodes with $300 \mathrm{~mm}^{2}$ geometrical area after performing cyclic voltammetry experiments with 100 cycles in the respective aqueous electrolyte solution

\begin{tabular}{|c|c|c|c|c|c|c|c|c|}
\hline \multirow[b]{2}{*}{$\begin{array}{l}\text { Working } \\
\text { electrode }\end{array}$} & \multicolumn{4}{|c|}{ 6.0 М КОН } & \multicolumn{4}{|c|}{$5.8 \mathrm{M} \mathrm{ZnCl}_{2}$} \\
\hline & $\begin{array}{c}Q_{\text {Ox }} \\
(\mathrm{mC})\end{array}$ & $\begin{array}{c}m_{\mathrm{Ag}, \mathrm{Ox}} \\
(\mathrm{mg})\end{array}$ & $\theta_{\mathrm{Ox}}$ & $\begin{array}{c}\varphi \\
(\%)\end{array}$ & $\begin{array}{c}Q_{\text {Ox }} \\
(\mathrm{mC})\end{array}$ & $\begin{array}{c}m_{\mathrm{Ag}, \mathrm{Ox}} \\
(\mathrm{mg})\end{array}$ & $\theta_{\mathrm{Ox}}$ & $\begin{array}{c}\varphi \\
(\%)\end{array}$ \\
\hline Ag (reference) & 114 & 128 & 1.00 & 0.0 & 141 & 157 & 1.00 & 0.0 \\
\hline A (carbon black) & 0.09 & - & - & - & 0.11 & - & - & - \\
\hline A1 & 25.7 & 28.8 & 0.225 & 77.5 & 4.43 & 4.95 & 0.032 & 96.8 \\
\hline A1D & 3.30 & 3.69 & 0.029 & 97.1 & 0.11 & 0.12 & 0.001 & 99.9 \\
\hline A2 & 9.72 & 10.9 & 0.085 & 91.5 & 0.23 & 0.26 & 0.002 & 99.8 \\
\hline B (carbon black) & 0.13 & - & - & - & 0.23 & - & - & - \\
\hline B1 & 4.26 & 4.77 & 0.037 & 96.3 & 4.00 & 4.47 & 0.028 & 97.2 \\
\hline B1D & 4.39 & 4.91 & 0.038 & 96.2 & 0.70 & 0.79 & 0.005 & 99.5 \\
\hline B2 & 4.36 & 4.88 & 0.038 & 96.2 & 0.38 & 0.43 & 0.003 & 99.7 \\
\hline
\end{tabular}

Except for the samples A1 and B1 which both evince slightly lowered passivation capabilities, working electrodes examined in the $5.8 \mathrm{M} \mathrm{ZnCl}_{2}$ electrolyte solution exhibit generally increased durability with almost no depletion of passivation capability. Qox values are arranged on same scale as values of bare carbon black WE that were determined as the limiting conditions (bold values in Table 2). Regardless of the selected printing ink, all WE samples examined in the $\mathrm{KOH}$ electrolyte reveal a decline in remaining passivation capability when compared to the samples tested in the $5.8 \mathrm{M} \mathrm{ZnCl}_{2}$ electrolyte 
solution. This can be related to the extended penetration properties of the $6.0 \mathrm{M} \mathrm{KOH}$ electrolyte solution into the passivation layers. In consequence, the apparent electroactive area is increased and the subjacent silver is exposed in the event of pinholes or other spots showing inhomogeneities in layer characteristics. Increasing the printed passivation layer thickness or adjustment of the screen printing process to a sequential wet-on-dry printing of two carbon black layers are evidenced to be the most promising methods to maintain passivation capability.

\subsection{Post-mortem analysis of working electrodes}

Post-mortem scanning electrode microscopic (SEM) imaging was performed on selected WE samples examined in $6.0 \mathrm{M} \mathrm{KOH}$ electrolyte solution. Energy-dispersive spectroscopy (EDS) spot measurements were conducted on potentially damaged areas within the passivation layers to obtain additional information on the chemical composition of the spots.

The SEM image shown in Fig. 10a reveals inhomogeneity within the carbon black passivation layer of the WE sample A1. Bright flake-like particles are visible on top of the WE surface. The corresponding spectrum of an EDS spot measurement conducted on the flake-like particles is depicted in Fig. 10b. The characteristic silver peak located at $2.98 \mathrm{keV}$ dominates the spectrum and evidences a pinhole-related exposure of the subjacent silver layer [55]. This confirms the progression of the red dash-dotted loop illustrated in the voltammogram of Fig. 9a indicating increased values for the anodic $(28 \mathrm{~mA})$ and cathodic (-28 mA) peak currents. In consequence, a reduced remaining passivation capability of $77.5 \%$ was obtained for this WE sample after completion of the 100 cycles during the CV experiment. Therefore, it can be assumed that a $6 \mu \mathrm{m}$ thick single-printed carbon black layer provides insufficient protection versus the $6.0 \mathrm{M}$ alkaline $\mathrm{KOH}$ electrolyte due to an increased risk of pinholes in the passivation layer.

a)

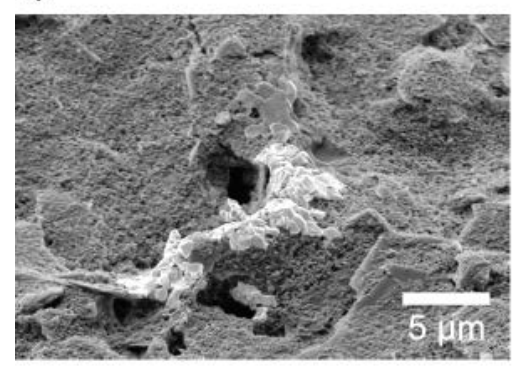

c)

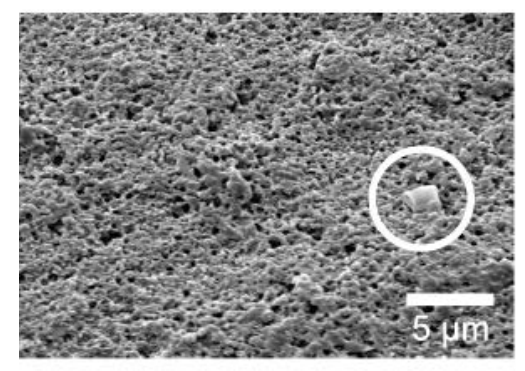

b)

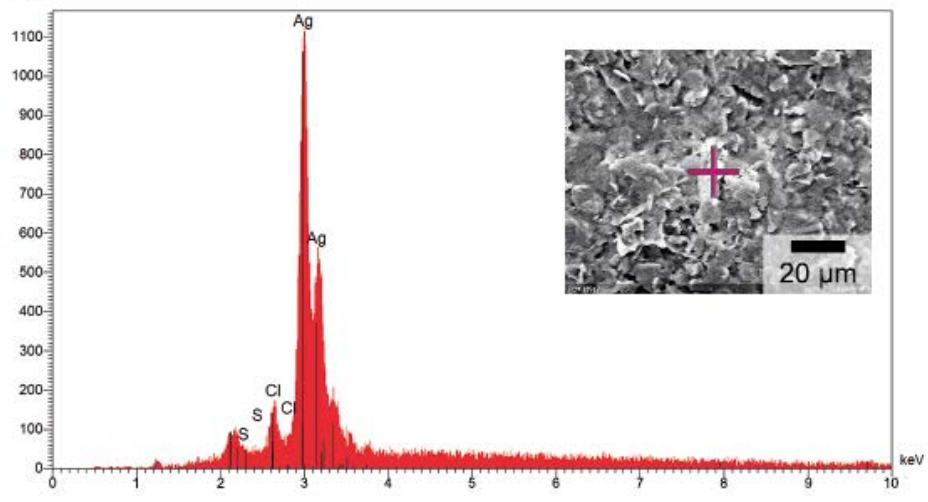

d)

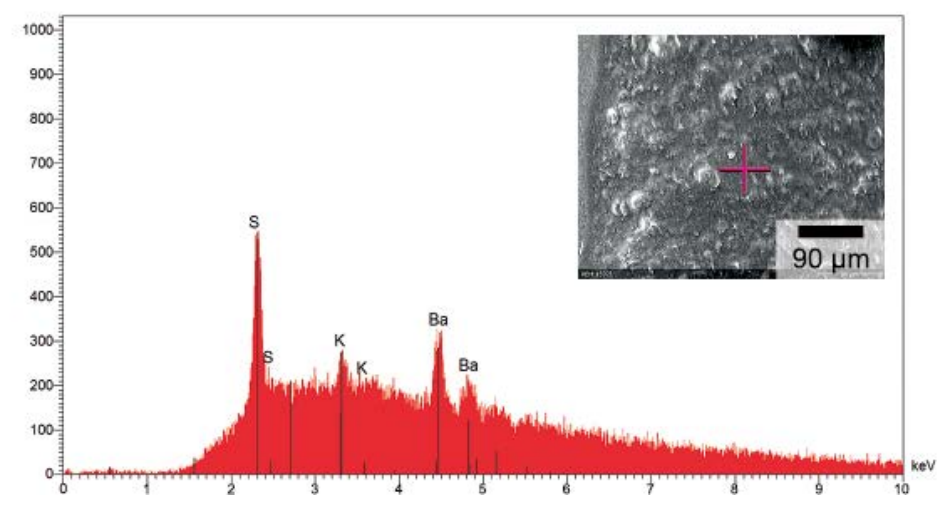

Fig. 10 (a) SEM image of the WE sample A1 examined in $6.0 \mathrm{M} \mathrm{KOH}$ electrolyte solution identifying a defect in the carbon black passivation layer; (b) EDS spectrum of a spot measurement on the defective passivation layer of the WE sample A1; (c) SEM image and (d) EDS spectrum of the WE sample B1 after performing 100 cycles in 6.0 M KOH electrolyte solution 
Fig. 10c presents a SEM image of the surface of the WE sample B1 analysed in 6.0 M KOH electrolyte solution. At the right side of the image, a single flake-like particle is recognisable on top of the WE surface. Analysis of this area by an EDS spot measurement reveals no silver related peaks located in the range of $3 \mathrm{keV}$ in the EDS spectrum (Fig. 10d) verifying the excellent passivation capability. However, the EDS spectrum reveals a completely different chemical composition for the carbon black material of the SD 2842 HAL ink compared to the sample A1 which was passivated by the PF 407 C ink. Peaks of sulphur (2.30 keV) and barium (4.46 keV) are noticeable. Yet, those elements seem to have no negative effect on the passivation capability of the analysed WE samples printed with the SD 2842 HAL carbon black ink.

\section{Conclusion}

A mathematical approach based on Faraday's law of electrolysis enables transformation of cyclic voltammetry curve progressions into directly comparable values. Instead of interpreting a large number of cyclic voltammograms, it is now possible to quantitatively compare individually fabricated passivation layers for metallic current collectors.

Silver working electrodes with $300 \mathrm{~mm}^{2}$ geometrical area were fabricated to simulate current collectors with low ohmic resistance for printed battery applications. Carbon black passivation layers in the range from $6.0 \mu \mathrm{m}$ to $24.8 \mu \mathrm{m}$ were subsequently printed to prevent the metallic working electrodes from corrosive damage. Cyclic voltammetry in three-electrode arrangement was used to evaluate possible electrochemical interaction of non-passivated and carbon black passivated working electrodes in $6.0 \mathrm{M}$ $\mathrm{KOH}$ and $5.8 \mathrm{M} \mathrm{ZnCl}_{2}$ aqueous electrolyte solutions.

Regardless of the passivation layer thickness and the solids content of the respective carbon black printing ink, overall reduction of passivation capability was observed for working electrode samples tested in the $6.0 \mathrm{M} \mathrm{KOH}$ electrolyte solution. This result can be attributed to the aggressive character $(\mathrm{pH}>14)$ of the alkaline $\mathrm{KOH}$ electrolyte resulting in distinctive penetration into and beneath the passivation layers. Due to pinhole related defects, a single-printed carbon black passivation layer thickness of $6.0 \mu \mathrm{m}$ revealed insufficient passivation properties. Verified by EDS measurements, small spots of the subjacent silver layer were accessible by the $\mathrm{KOH}$ electrolyte resulting in an increase of the peak currents in the respective voltammogram. The damage to the passivation layer was reflected by a decrease of the corresponding remaining passivation capability to $77.5 \%$ after 100 cycles. Alkaline $\mathrm{KOH}$ electrolytes require printing of passivation layers with a highly filled carbon black printing ink ( $80 \mathrm{wt} . \%)$ or a double print wet-on-dry with a conventional carbon black ink to ensure adequate passivation properties.

In contrast, enhanced durability was registered for carbon black passivated silver working electrodes examined in the acidic 5.8 $\mathrm{M} \mathrm{ZnCl}_{2}$ electrolyte solution (pH: 2.3). Remaining passivation capabilities of more than $96 \%$ were determined after completion of 100 cycles during the CV experiments. The overall improved resistance of the differently prepared passivation layers towards this acidic electrolyte makes this electrolyte attractive for printed battery applications demanding a long-life cycle.

Besides other commercially available carbon black printing inks, the performance of alternative materials or newly designed printing inks such as graphene based inks can now be compared to previous standard materials.

\section{Acknowledgements}

The authors would like to thank Dr.-Ing. Jonas Bartsch (Fraunhofer Institute for Solar Energy Systems ISE, Freiburg i.Br., Germany) for inspiring discussions on cyclic voltammetry experiments. Thanks are also due to Ulf Müller (Institute of Plastics Engineering IKT, Stuttgart University, Stuttgart, Germany) for EDS measurements on printed working electrode samples. 


\section{Declarations}

\section{Funding}

Not applicable.

\section{Conflict of interest}

The authors declare they have no potential conflict of interest.

\section{Availability of data and material}

All data generated and analysed during this study are included in this published article and its supplementary information file.

\section{Code availability}

Not applicable.

\section{Authors' contributions}

All authors contributed to the study conception and design. Material preparation, data collection and analysis were performed by P.R., E.S. and M.K. The first draft of the manuscript was written by P.R. and all authors commented on previous versions of the manuscript. All authors read and approved the final manuscript.

\section{References}

1. A.J. Bandodkar, W. Jia, J. Wang, Electroanalysis 27, 562 (2015)

2. Y. Khan, D. Han, A. Pierre, J. Ting, X. Wang, C.M. Lochner, G. Bovo, N. Yaacobi-Gross, C. Newsome, R. Wilson, A.C. Arias, Proceedings of the National Academy of Sciences of the United States of America 115, E11015-E11024 (2018)

3. Y. Liu, M. Pharr, G.A. Salvatore, ACS nano 11, 9614 (2017)

4. T.R. Ray, J. Choi, A.J. Bandodkar, S. Krishnan, P. Gutruf, L. Tian, R. Ghaffari, J.A. Rogers, Chem. Rev. 119, 5461 (2019)

5. S.P. Sreenilayam, I.U. Ahad, V. Nicolosi, V. Acinas Garzon, D. Brabazon, Materials Today 32, 147 (2020)

6. Intellilog, Technical product data sheet: Intellilog End-to-End Cold Chain Monitoring, https://intellilog.io/assets/downloads/brochure.pdf (2017)

7. H. Kang, H. Park, Y. Park, M. Jung, B.C. Kim, G. Wallace, G. Cho, Scientific reports 4, 5387 (2014)

8. A. Pereira, E. Bergeret, O. Benzaim, J. Routin, O. Haon, L. Tournon, R. Coppard, G. Depres, Flex. Print. Electron. 3, 14003 (2018)

9. P. Rassek, M. Wendler, M. Krebs, in Printed Batteries, ed. by S. Lanceros-Méndez, C.M. Costa (John Wiley \& Sons, Ltd Chichester, UK, 2018), p. 185

10. A. Willert, R.R. Baumann, in 2013 International Semiconductor Conference Dresden-Grenoble (ISCDG), ed. by G. Schmidt (IEEE Piscataway, NJ, 2013), p. 1

11. A. Willert, A. Kreutzer, U. Geyer, R.R. Baumann, in Smart systems integration 2009, ed. by T. Gessner (AKA Verl. Heidelberg, 2009), p. 556

12. K.T. Braam, Development of an air-stable, high energy density printed silver oxide battery for printed electronics. Ph.D. Thesis (University of California, 2014)

13. K.-H. Choi, D.B. Ahn, S.-Y. Lee, ACS Energy Lett. 3, 220 (2018)

14. A.M. Gaikwad, D.A. Steingart, T. Nga Ng, D.E. Schwartz, G.L. Whiting, Appl. Phys. Lett. 102, $233302(2013)$ 
15. B.J. Kim, J.W. Evans, P.K. Wright, J. Phys.: Conf. Ser. 1052, 12012 (2018)

16. R.E. Sousa, C.M. Costa, S. Lanceros-Méndez, ChemSusChem 8, 3539 (2015)

17. Z. Tehrani, T. Korochkina, S. Govindarajan, D.J. Thomas, J. O’Mahony, J. Kettle, T.C. Claypole, D.T. Gethin, Organic Electronics 26, 386 (2015)

18. Y. Wang, H. Kwok, W. Pan, H. Zhang, D.Y.C. Leung, Journal of Power Sources 414, 278 (2019)

19. Enfucell, Technical specifications for Softbattery Reg 1.5V, Mini 1.5V and 3654 3.0 V, Reg 1.5V Plus, Mini 1.5V Plus (Vantaa, 2019)

20. A. Saidi, L. Desfontaines, A. Champeval, J.-D. Lebreux, C. Lecomte, M. Pruneau, A. Grondein, R. Izquierdo, D. Bélanger, Flex. Print. Electron. 2, 15002 (2017)

21. A. Willert, C. Meuser, R.R. Baumann, Jpn. J. Appl. Phys. 57, 05GB02 (2018)

22. E. Madej, M. Espig, R.R. Baumann, W. Schuhmann, F. La Mantia, Journal of Power Sources 261, 356 (2014)

23. M.G. Choi, K.M. Kim, Y.-G. Lee, Current Applied Physics 10, e92-e96 (2010)

24. M. Wendler, E. Steiner, T.C. Claypole, M. Krebs, Journal of Print and Media Technology Research III, 241 (2014)

25. B. Kim, R. Winslow, I. Lin, K. Gururangan, J. Evans, P. Wright, J. Phys.: Conf. Ser. 660, 12009 (2015)

26. Y.-G. Lee, M.-G. Choi, K.-Y. Kang, K.-M. Kim, Journal of Electrochemical Science and Technology 1, 39 (2010)

27. M. Wendler, G. Hübner, M. Krebs, International Circular of Graphic Education and Research 4, $32(2011)$

28. A. Willfahrt, T. Fischer, S. Sahakalkan, R. Martinez, M. Krebes, E. Steiner, Flex. Print. Electron. 3, 45004 (2018)

29. P. Rassek, E. Steiner, M. Herrenbauer, T.C. Claypole, Flex. Print. Electron. 4, 35003 (2019)

30. K.-Y. Kang, Y.-G. Lee, D.O. Shin, J.-C. Kim, K.M. Kim, Electrochimica Acta 138, 294 (2014)

31. M. Montanino, G. Sico, A. de Girolamo Del Mauro, M. Moreno, Membranes 9 (2019)

32. A.E. Ostfeld, A.M. Gaikwad, Y. Khan, A.C. Arias, Scientific reports 6, 26122 (2016)

33. S. Lanceros-Méndez, C.M. Costa (eds), Printed Batteries: Materials, technologies and applications (John Wiley \& Sons, Ltd, Chichester, UK, 2018)

34. D.M.E. Garcia, A.S.T.M. Pereira, A.C. Almeida, U.S. Roma, A.B.A. Soler, P.D. Lacharmoise, I.M. das Mercês Ferreira, C.C.D. Simão, ACS omega 4, 16781 (2019)

35. S. Berchmans, A.J. Bandodkar, W. Jia, J. Ramírez, Y.S. Meng, J. Wang, J. Mater. Chem. A 2, 15788 (2014)

36. R.E. Sousa, J. Oliveira, A. Gören, D. Miranda, M.M. Silva, L. Hilliou, C.M. Costa, S. LancerosMendez, Electrochimica Acta 196, 92 (2016)

37. T. Ma, J. Devin MacKenzie, Flex. Print. Electron. 4, 15010 (2019)

38. C. Stangl, B. Fuchsbichler, M. Schmuck, S. Koller, in Flexible carbon-based electronics, ed. by P. Samorí, V. Palermo, X. Feng (Wiley-VCH Weinheim, 2018), p. 265

39. A.M. Zamarayeva, A. Jegraj, A. Toor, V.I. Pister, C. Chang, A. Chou, J.W. Evans, A.C. Arias, Energy Technol. 21, 1901165 (2019)

40. M. Wendler, G. Hübner, M. Krebs, in Advances in printing and media technology, Vol. XXXVII, ed. by N. Enlund, iarigai (International Association of Research Organisations for the Information Media and Graphic Arts Industries (IARIGAI) Darmstadt, 2010), p. 303

41. G. Hübner, M. Krebs, tm - Technisches Messen 80, 67 (2013)

42. A.J. Bard, L.R. Faulkner, Electrochemical methods: Fundamentals and applications: Fundamentals and applications (Wiley, Hoboken, NJ, 2001)

43. D.K. Gosser, Cyclic voltammetry: Simulation and analysis of reaction mechanisms: Simulation and analysis of reaction mechanisms (VCH, New York, 1993)

44. C.G. Zoski, Handbook of electrochemistry (Elsevier, Amsterdam, 2007)

45. N. Elgrishi, K.J. Rountree, B.D. McCarthy, E.S. Rountree, T.T. Eisenhart, J.L. Dempsey, J. Chem. Educ. 95, 197 (2018)

46. N. Aristov, A. Habekost, WJCE 3, 115 (2015) 
47. K.W. Beard, T.B. Reddy, D. Linden, Linden's handbook of batteries (McGraw-Hill, New York, 2019)

48. A.J. Bard, G. Inzelt, F. Scholz, Electrochemical Dictionary (Springer Berlin Heidelberg, Berlin, Heidelberg, 2012)

49. L.R. Faulkner, J. Chem. Educ. 60, 262 (1983)

50. M.d.S. Klem, R.M. Morais, R.J.G. Rubira, N. Alves, Thin Solid Films 669, 96 (2019)

51. J. Biener, M. Stadermann, M. Suss, M.A. Worsley, M.M. Biener, K.A. Rose, T.F. Baumann, Energy Environ. Sci. 4, 656 (2011)

52. F. Béguin, E. Frackowiak, Carbons for electrochemical energy storage and conversion systems (CRC, Boca Raton, 2010)

53. W.M. Haynes, D.R. Lide, CRC Handbook of Chemistry and Physics: A ready-reference book of chemical and physical data: A ready-reference book of chemical and physical data (CRC PressTaylor \& Francis, Boca Raton, 2011)

54. Q. Cheng, J. Tang, J. Ma, H. Zhang, N. Shinya, L.-C. Qin, Carbon 49, 2917 (2011)

55. JEOL Ltd., Energy Table for EDS analysis, https://www.jeolusa.com/DesktopModules/LiveContent/API/Image/Get?mid=4725\&eid=1\&Typ $\mathrm{e}=$ View\&PortalId=2 (2006) 